http://dx.doi.org/10.18232/alhe.1008

Artículos

\title{
Más allá de los sumarios de cargo y data: un acercamiento a las cuentas de la Caja Real de Santafé en la segunda mitad del siglo XVIII
}

\section{Beyond the Summaries of Cargo and Data: An Approach to the Accounts of the Royal Treasury of Santafe in the Second Half of the 18th Century}

José J. Pinto ${ }^{1,}$ * [D 0000-0003-0791-4043

${ }^{1}$ Universidad del Tolima, Ibagué-Tolima, Colombia.

*Correspondencia: josejoaqo@yahoo.com

Resumen. Este artículo estudia las trasformaciones de las prácticas contables en la Caja Real de Santafé en el virreinato de Nueva Granada durante la segunda mitad del siglo XviII. Para tal objetivo se han utilizado las disposiciones legales en la materia, los manuales para la elaboración de cuentas y algunos informes de encargados del manejo de la Real Hacienda. El ejercicio permite aclarar las razones por las que varios estudios sobre la caja difieren en términos cuantitativos debido a la falta de compresión de la lógica contable, con base en lo cual se propone el empleo de los Estados Generales de Ingreso, Egreso y Deuda para futuros trabajos que busquen establecer el movimiento de la tesorería, ya que estos brindan información más puntual que la consignada en los sumarios generales de cargo y data.

Palabras clave: tributación; series cuantitativas; contabilidad.

CÓMO CITAR: Pinto, J. J. (2020). Más allá de los sumarios de cargo y data: un acercamiento a las cuentas de la Caja Real de Santafé en la segunda mitad del siglo XVIII. América Latina en la Historia Económica, 27(1), e1008. DOI:10.18232/alhe.1008 
Abstract. This article studies the transformations of accounting practices in the royal treasury of Santafe in the Viceroyalty of New Granada during the second half of the 18th century. For this purpose, we used the legal dispositions in the matter, the manuals for the preparation of accounts and some reports of oficiales reales of the Royal Treasury. The exercise makes it possible to clarify the reasons why several studies about the treasury differ in quantitative terms due to the lack of understanding of the accounting logic. Based on it, we propose the use of the General Income, Exit and Debt States for future researches that look for to establish the movement of the treasury since these provide more punctual information that the consigned in the general summaries of charge and data.

Key words: taxation; quantitative series; accounting.

JEL: F54; N96.

Recibido: 24 de julio de 2018.

Aceptado: 24 de octubre de 2018.

Publicado: 1 de septiembre de 2019.

\section{INTRODUCGIÓN}

La historiografía sobre la Real Hacienda en Nueva Granada durante el siglo xviII ha fincado sus esfuerzos en la determinación de los niveles de recaudo y gasto con base en los sumarios generales de cargo y data, bien para establecer el comportamiento de la dinámica económica o para determinar el grado de presión ejercida por el fisco y el nivel de gestión del estado colonial en términos de gasto.

Estos trabajos pueden ser clasificados en dos grupos, el primero involucra las visiones que incluyen el grueso del virreinato. Algunos de ellos dan cuenta del desempeño económico a través de los cargos y datas de las cajas reales, como en el caso de Meisel (2011a), mientras que otros dan cuenta del proceso de la consolidación del aparato político (Pinto, 2016, 2018), algunas investigaciones logran desentrañar los pormenores del sector gremial y su vinculación con el ámbito fiscal (Arévalo y Rodríguez, 2001). Otras investigaciones han logrado determinar el movimiento de los flujos comerciales con base en los libros de alcabalas (Moreno, 2013; Muñoz y Torres, 2013), construyendo una visión amplía del desempeño económico con base en el estudio del comportamiento del sector minero (Torres, 2013) o del mercado de crédito (Torres, 2014).

Otro grupo de pesquisas, basadas en una visión de orden regional, han estudiado el comportamiento de las series en tesorerías particulares, como en el caso de Santafé donde encontramos los textos de Pinto (2015) y Muñoz (2010); Cartagena, que ha sido estudiada por Marchena (2005), Serrano (2004b), Meisel (2011b), Arévalo y Rodríguez (2008); Popayán, que ha sido explorada por Rodríguez (1987) y en un reciente artículo por Pinto y Díaz (2016), además del estudio sobre Panamá de Pinto (2014). Partiendo de algunas de estas exploraciones, el trabajo de Kalmanovitz y López (2012) permitió observar el comportamiento favorable de la economía de Santafé antes del periodo de la independencia, obra que, aunque no se trata en estricto sentido de una historia fiscal, sí da cuenta del empleo de los indicadores fiscales como herramienta de acercamiento al sector real de una región específica.

A pesar de esta considerable producción, muy pocas investigaciones se han encargado de hacer una discusión metodológica en torno a las fuentes citadas (sumarios de cargo y data), haciendo caso omiso a las advertencias que en su tiempo hiciera uno de los principales promotores de su 
empleo (Klein, 1994) respecto de las dificultades de dicha fuente para registrar ingresos y egresos efectivos. Al interior de este rastreo hemos podido constatar que la discusión más profunda sobre la naturaleza de la contabilidad de las cajas reales y que ha sido aplicada al caso de Nueva Granada es la desarrollada por Serrano. Este autor identifica una serie de trampas contables que pueden inducir a los investigadores a registrar ingresos y egresos de manera errónea, mismas que se presentan como producto de las denominaciones encubiertas de algunos gastos, el poco cuidado con los remanentes - no sólo del total, sino también de cada ramo-, y el complejo mecanismo de la devolución de los préstamos y las trasferencias que se registraban al interior de los ramos, pero no como un rubro independiente (Serrano, 2006). Serrano (2002) también ha podido constatar cómo los cargos incluían los movimientos de la caja y no solamente las entradas o salidas de numerario, como se presenta en el registro de lo debido cobrar. Estos preceptos fueron aplicados por Serrano (2004a) para el desarrollo de su estudio sobre el gasto militar de las costas neogranadinas.

Aunque los problemas del registro contable se pueden interpretar como simples rudimentos técnicos propios de los contadores de la Real Hacienda, Sánchez (2013, p. 21) ha clarificado que a pesar de la aplicación por parte de la mayoría de trabajos sobre la Real Hacienda en América del método empleado por Klein (1973) para la depuración de las partidas dobles en los sumarios de cargo y data, y de allí extractar el ingreso efectivo, este procedimiento no es del todo exacto en la medida en que los sumarios al constituirse en un resumen de los libros comunes, no sólo reportan los movimientos de efectivo, sino también el monto de múltiples aspectos que hacen parte de las obligaciones propias de los oficiales reales. Así, los sumarios generales nos darían una sobrevaloración del ingreso y egreso, pues incluyen partidas que no constituían el movimiento efectivo de caudales, sino el registro de montos que daban cuenta de las responsabilidades de los encargados del manejo de las tesorerías.

Como resultado, cada uno de los diversos trabajos presenta montos diferenciados a pesar de utilizar las mismas fuentes, problema que radica en la falta de análisis de las prácticas contables del antiguo régimen en el territorio de Nueva Granada. Este campo de estudios ha contado con distintos aportes desde tiempo atrás en el ámbito continental, gracias al trabajo de Donoso (1997), quien desarrolló un completo estudio de la instauración de la reforma contable de partida doble gestionada por Machado Fiesco en 1784, dando cuenta de sus principales antecedentes y obstáculos, así como la aplicación de dicha media en el caso específico del virreinato de Lima (Donoso, 2001), obras que estuvieron acompañadas del estudio pormenorizado de las formas de control y registro desarrolladas para su aplicación en las cajas reales americanas durante el gobierno de los Austrias (Donoso, 2008).

Estos esfuerzos fueron ampliados recientemente a través de ejercicios que evalúan la instauración de la partida doble en España y México desde una perspectiva comparada, dando cuenta de su impacto en el sector público y en compañías privadas hasta bien entrado en el siglo XIx (Bátiz-Lazo, Hernández, Maixé-Altés y Núñez, 2012). Por otra parte, el trabajo de Sánchez (2013) permitió evidenciar la aparición de un nuevo tipo de documental para un registro cabal de los ingresos y gastos de la corona en Nueva España (Relaciones de Valores y Distribución), que forman parte del paquete de reformas efectuadas durante la primera mitad del siglo xviII, esfuerzo que fue complementado con el estudio del contenido y ejecución en Nueva España de las instrucciones elaboradas por Ortiz y Landázuri en 1766 y 1767 para la unificación del método de elaboración de los cortes de caja y presentación de cuentas en América (Sánchez, 2019). 
Teniendo como punto de partida estos referentes, el presente trabajo da cuenta del desarrollo de la reforma contable en la caja de Santafé (matriz del virreinato de Nueva Granada) a través del estudio de las disposiciones reales que agenciaron su aparición. En un primer apartado se puntualiza el problema del registro contable a través de diversas fuentes documentales para la oficina recaudadora que nos ocupa; en el segundo, se describen los pormenores de las reformas y las prácticas contables entre 1765 y 1791, mientras que en el tercer apartado se estudia la instauración de dichas reformas en la Caja Real de Santafé, dando cuenta de las características de los diversos tipos documentales que sus oficiales generaron; por último, las conclusiones.

\section{Mismas FUENTES CON RESUltados DisPaRes}

En este apartado se expone de manera puntual cómo diversos trabajos que se han ocupado de la Caja Real de Santafé reportan resultados diversos en términos cuantitativos, ejercicio que posibilita dimensionar el problema que nos ocupa, mismo que va más allá de una simple aclaración técnica del ejercicio contable. En un primer momento se ubica el papel de Santafé para la Real Hacienda en Nueva Granada, posteriormente se comparan los resultados de los cargos registrados en los sumarios empleados en los trabajos de Meisel (2011a) y Pinto (2016), después de ello comparamos la disparidad entre los resultados de Pinto (2016) y los estados generales de ingreso y egreso elaborados por los oficiales de la corona. Este balance deja clara la disparidad de los resultados al trabajar con las mismas fuentes o al comparar estas con otros tipos documentales, permitiendo la emergencia de algunos cuestionamientos que sirven de guía a nuestro trabajo.

La Caja Real de Santafé era el epicentro de la recaudación de los sobrantes de sus subalternas a lo largo y ancho del virreinato de Nueva Granada. Cada una de las cajas diseminadas en su entorno estaban en la obligación de cubrir las erogaciones propias de su jurisdicción y disponer del excedente con destino a la capital del virreinato. Con base en estos fondos más los generados en la región, Santafé estaba obligada a cubrir las operaciones propias del gobierno central, las cuales una vez descontadas de la gruesa ingresada, arrojaban un sobrante cuyo destino final sería Cartagena (Rodríguez, 1983). En tal contexto, Santafé estaba integrada a uno de los frentes de defensa del dominio imperial, específicamente a aquel encargado de salvaguardar el sur del Mar Caribe (Jara, 2011), que tenía como principal bastión a la ciudad de Cartagena, la cual no sólo recibía remisiones de la capital, sino también de Quito (Jara, 1994).

Este panorama de circulación de fondos era complementado con la de documentos contables, toda vez que la capital era sede del Tribunal Mayor de Cuentas. Como bien es sabido, los oficiales de cada una de las cajas reales estaban encargados de llevar los libros particulares (pertenecientes a cada encargado) así como el libro común donde se registraban todas las transacciones ordenadas ramo a ramo, siendo firmadas cada una por todos los oficiales, además del libro ma-

nual donde se registraban las operaciones ordenadas cronológicamente, rutina que se desarrollaba desde tiempo de los Austrias (Donoso, 2008). Con base en dichos documentos, los encargados de cada caja debían elaborar -a fin de cada año- un corte y tanteo donde daban cuenta de los ingresos y egresos de la misma, además de una cuenta donde se detallaran los movimiento registrados en el libros común, documentos que debían ser enviados, junto con la relación jurada (resumen del cargo y data), al Tribunal Mayor de Cuentas, donde eran revisadas para determinar los alcances en favor o en contra del erario regio, y posteriormente ser enviados a la Contaduría de Indias donde se les daría el finiquito correspondiente. 
En este contexto, los trabajos que se han ocupado de la Caja Real de Santafé han empleado fundamentalmente los sumarios de cargo y data extractados de los libros comunes, ejercicio que arroja resultados diferenciales. Este fenómeno es producto del empleo de metodologías distintas basadas en el método propuesto por Klein (1973) y que se puede resumir en: $a$ ) agrupación de los ramos de cargo por actividades económicas en seis grandes clases (minería, comercio y producción, tributo indígena, pagos burocráticos, monopolios, y varios); b) agrupación de los ramos de data por funciones de gobierno en cinco grandes clases (sueldos políticos y de justicia, sueldos de Real Hacienda, sueldos de tropa y gastos militares, sueldos eclesiásticos, y varios), y c) eliminación de dobles partidas y presuntos ingresos no efectivos.

Este método, aunque útil en su momento, ha recibido fuertes críticas debido a la aparición de lo que Serrano (2006) llamaría la trampa contable, pues el solo uso de los sumarios de cargo y data no es suficiente para la determinación de lo recaudado y gastado, ya que, en algunos casos, ciertos gastos -sobre todo de carácter militar- se encontraban bajo denominaciones que no necesariamente hacían referencia a erogaciones de tipo bélico, sino a gastos de administración. Los remanentes o existencias de años anteriores no sólo se encontraban en el sumario general, sino que eran parte constitutiva de la sumatoria de cada uno de los ramos; por tanto, el sumario, además de contener la existencia total del año anterior en la caja, incluía también los sobrantes de cada ramo sin discriminarlos. La devolución de préstamos debe ser sustraída de las datas militares del año en que eran devueltos, ya que podía haber sido computada en el año en que se tomó el crédito, de lo contrario, se contarían de manera doble. También existían situados que no se registraban en los sumarios como remisiones, sino confundidos al interior de cada uno de los ramos.

Así, los sumarios de cargo y data no son del todo útiles para la comprensión de los ingresos y egresos de cada caja, por lo que su estudio debería estar acompañado del cotejo de los libros comunes de los cuales provenían (Serrano, 2006), lo que había sido ya reconocido por Klein (1994). A pesar de ello, para el caso de la Caja Real de Santafé se recurrió a la metodología de Klein sin tomar en cuenta los reparos críticos a la misma y con adaptaciones particulares. Un ejemplo de lo anterior lo constituyen los trabajos de Meisel (2011a) y Pinto (2016), cuyos resultados compararemos a continuación.

Meisel (2011a) agrupó las cajas reales de la región central de Nueva Granada (Santafé, Pamplona, Girón, Honda, Ibagué y Ocaña) por quinquenios, usando parcialmente la agregación de ramos por actividades económicas con arreglo a la metodología propuesta por Klein (1973). Realizar un ejercicio de comparación resulta difícil debido a que Meisel (2011a) no nos ofrece un listado de los ramos que fueron agrupados; sin embargo, la aplicación parcial de la metodología de Klein (1973) permitió que el autor dejara sin agregar dos de las principales fuentes de ingreso para ser evaluadas (tabacos y aguardiente) con base en las cuales haremos un comparativo. Por otra parte, Meisel (2011a) presenta un rubro que titula "comercio interno" del cual desconocemos los ramos de los que está compuesto. En este contexto, tomaremos las cifras de Meisel (2011a) pertenecientes al quinquenio 1776-1780 y las compararemos con las de Pinto (2016), que se encuentran discriminadas por cajas, año por año y por rubros. Desafortunadamente este último trabajo sólo nos ofrece las cajas de Santafé, Ocaña, Honda e Ibagué (véase gráfica 1).

El ejercicio arroja como resultado que las cifras de Pinto (2016) en los tres rubros (aguardiente, tabaco, alcabala) son mayores que las de Meisel (2011a) a pesar de que el primero sólo incluye cuatro de las seis cajas agrupadas por el segundo. Por otra parte, usamos sólo las cifras de alcabalas aportadas por Pinto (2016) y las comparamos con lo que Meisel (2011a) llamó comercio interno, que se supone incluye otros rubros como camellón, nuevo impuesto, sisa o avería, y, aun así, la cifra 


\section{GRÁFICA 1. COMPARATIVO DE LOS CARGOS REGISTRADOS EN ALGUNOS RAMOS PARA LAS CAJAS REALES DE LA REGIÓN GENTRAL DE NUEVA GRANADA, 1776-1780}

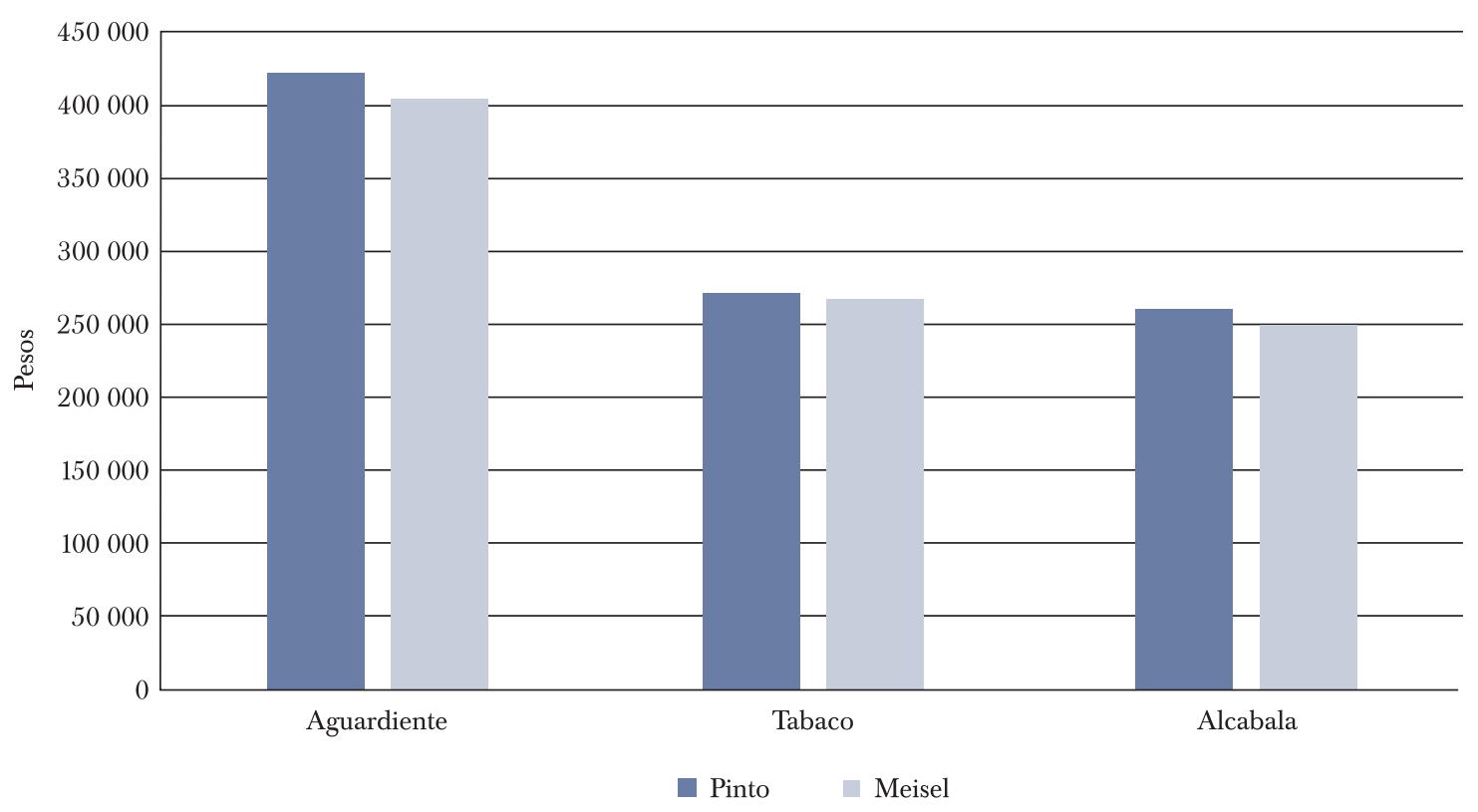

Fuente: elaboración propia con base en Meisel (2011a) y Pinto (2016).

de Pinto sigue siendo mayor. ¿Cómo es posible que un solo rubro supere el valor de la agrupación de varios? ¿Cómo es posible que tres de los principales ramos arrojen sumas superiores agrupando cuatro y no seis cajas reales? Así, las cifras de Meisel (2011a) reportan un subrregistro difícil de cotejar pues en su trabajo no reportó cuáles fueron los ramos agregados en cada clase y tampoco incluye las cifras anuales ni discriminadas por cajas. Pero, aun así, las de Pinto (2016) -aunque no están agrupadas regional o temporalmente- siguen siendo sumarios de cargo y data, por lo que contienen los errores señalados por Serrano (2006).

La situación se vuelve más compleja si comparamos los cargos e ingresos totales. Para ello se ha empleado el total de los cargos de los sumarios generales, la depuración de estos eliminando dobles partidas, como lo propone Klein (1973), y el total de los ingresos efectivos registrados en los estados de los valores y pensiones en la Caja Real de Santafé (véase gráfica 2).

La diversidad vuelve a ser evidente, ya que los ingresos efectivos son inferiores en 914598 pesos respecto de los sumarios sin depurar, y de 595509 respecto de los sumarios eliminando las dobles partidas. ¿A qué se debe esta diversidad? ¿Cuál de las metodologías empleadas y de los tipos documentales nos acerca más al ingreso y gasto efectivo de la Caja Real de Santafé? La respuesta a estas preguntas puede encontrarse tras el análisis de la evolución de las fuentes contables durante la segunda mitad del siglo XviII en Nueva Granada, ejercicio que proponemos a través de la determinación de la naturaleza de cada uno de los tipos documentales, con base en el estudio de las disposiciones que les dieron origen. 


\section{GRÁFICA 2. COMPARATIVO DEL TOTAL DE CARGOS E INGRESOS EN LOS SUMARIOS GENERALES Y LOS ESTADOS DE INGRESO Y EGRESO DE LA CAJA REAL DE SANTAFÉ ENTRE 1777 Y 1784}

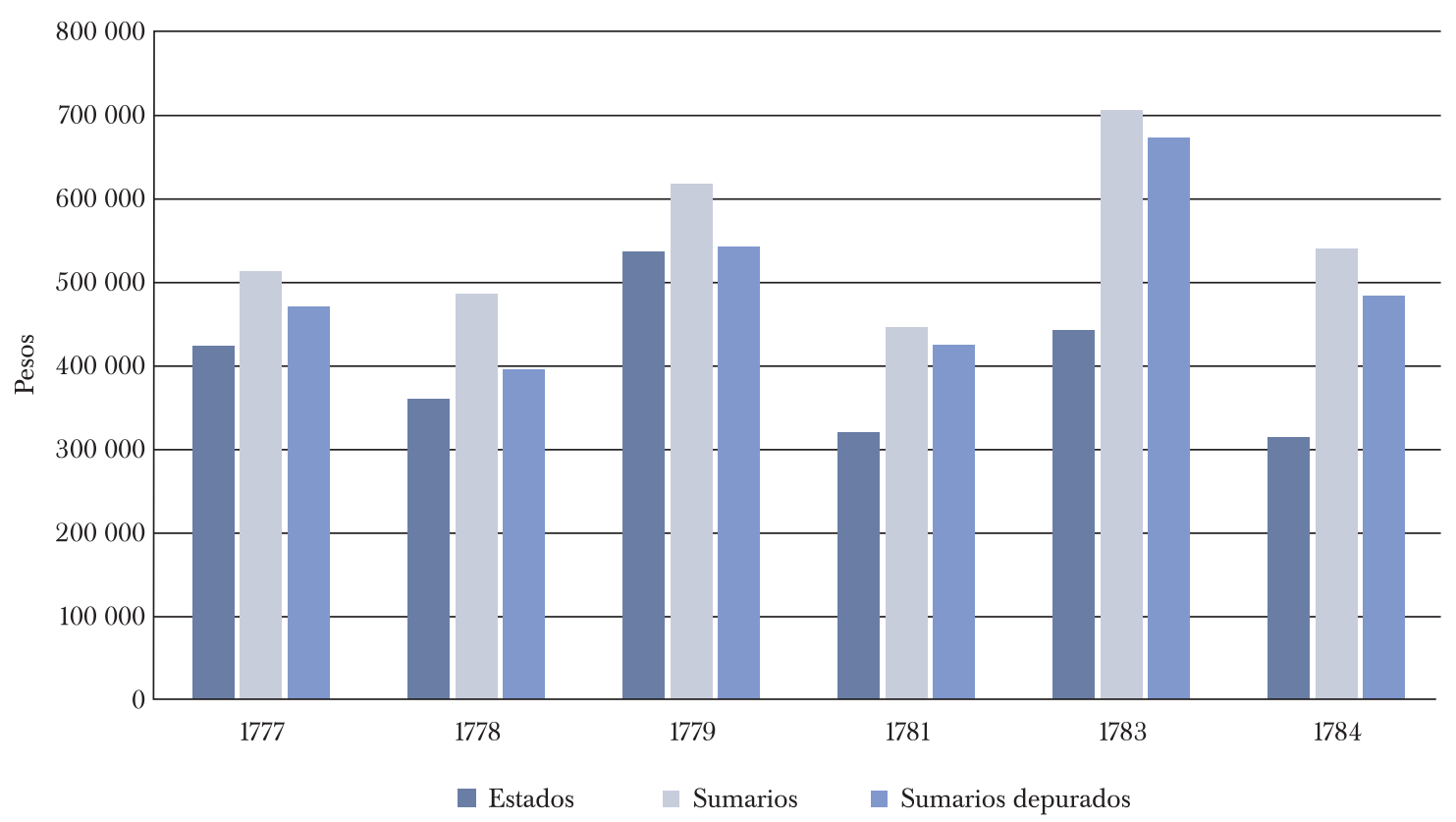

Fuente: elaboración propia con base en Archivo General de Indias (en adelante AGI), Santa Fe, 784, y John Jay TePaske Papers, 1500s-1988, caja 3, carpetas 1 y 2.

\section{La contabilidad de las Cajas Reales de Nueva Granada EN LA SEGUNDAD MITAD DEL SIGLO XVIII}

Desde la instauración del Tribunal Mayor de Cuentas de Santafé en 1605 los oficiales reales estuvieron obligados a la presentación de sus cuentas a dicha instancia con el fin de que estas fueran revisadas y fenecidas por los contadores, de tal suerte que si se presentaban alcances en favor de la Real Hacienda sus encargados quedaban comprometidos a adelantar las diligencias propias para lograr su satisfacción. Los oficiales de las cajas reales debían remitir a Santafé relaciones juradas de todo lo que hubieran recibido y gastado, obligándose a responder con sus bienes y personas en caso de constatarse inconsistencias (Rojas, 2001), relaciones que debían estar en total correspondencia con el libro común de cada caja (p. 160).

Enviadas las relaciones juradas y verificada su correspondencia con los libros, los oficiales enviaban directamente al Consejo de Indias el corte y tanteo de la caja, lo cual debía hacerse al comenzar el año con clara distinción de lo cobrado, lo gastado y lo debido cobrar, discriminando cada ramo y determinando las causas por las cuales se habían presentado alcances si los hubiere (Rojas, 2001, p. 129).

Así, desde comienzos del siglo xvi ya se tenía conocimiento por parte de los oficiales reales de cada caja, y desde inicios del xvi por los contadores del Tribunal Mayor de Cuentas, de las obligaciones de llevar el libro común, efectuar las relaciones juradas y remitir los cortes y tanteos anuales de caja al Consejo de Indias; sin embargo, hasta bien entrado el siglo XviII, no se tenía claridad so- 
bre los procedimientos a seguir para la elaboración de los cortes de caja, lo que provocaba que la información de la que disponía la corona era poco fiable y altamente diversa, imposibilitando conocer con exactitud el verdadero estado de la Real Hacienda, como lo denota la real orden del 29 de marzo de 1749 expedida para todas la Indias y de la cual se tuvo pleno conocimiento en Santafé, donde se reitera el requerimiento del envío de las cuentas a España con plena distinción de lo cobrado, lo gastado, lo existente y sobrante 1

Pese a ello, años después, el 11 de marzo de 1765, de nuevo el real servicio tuvo que manifestarse debido a la falta de cumplimiento de las reales disposiciones sobre el envío de relaciones puntuales que reportaran la dinámica de ingreso, egreso y deuda del Nuevo Reino de Granada, a través de una real orden dirigida al virrey:

Resultando considerables perjuicios de que en desprecio de lo prevenido por las leyes, y reales órdenes faltan los oficiales reales de las cajas de ese reino, y también ese Tribunal, enviar anualmente las cuentas, y noticias de todos los productos de diezmos, novenos, vacantes mayores, y menores, mesadas, y demás ramos, que pertenecen a la Real Hacienda: ha resuelto el rey que vs cuide muy particularmente de que precisamente se remitan anualmente a su majestad y al consejo todas las expresas noticias, y que en la administración general de diezmos en que su majestad está interesado, se observen las justas leyes, y repetidas disposiciones que están dadas: y de su real orden lo participo a vs para su puntual cumplimiento, y que advierto a los ministros, que corresponde lo conveniente, a que le tenga. Dios guarde a vs muchos años [sic] ${ }^{2}$

Dicha diversidad e incumplimiento no sólo era exclusiva del Nuevo Reino de Granada, sino que se presentaba en gran parte de los dominios indianos, hecho que provocó la reforma del contador general del Consejo de Indias, Tomás Ortiz de Landázuri, y que culminaría con la promulgación de la instrucción práctica para la formación de cortes y tanteos del 18 de julio de 1766 (Sánchez, 2019). En dicha instrucción, el contador especificó que la finalidad de los cortes y tanteos era la de dar un panorama del estado de cada caja anualmente, objetivo que era muy distinto del de los sumarios generales empleados por el grueso de la historiografía para calcular los ingresos y egresos de cada oficina recaudadora, ya que estos últimos estaban pensados como mecanismos de control de las responsabilidades de los oficiales reales (Sánchez, 2013, p. 19), responsabilidades entre las que se incluían el cobro de deudas y el pago de alcances, muchos de los cuales eran incluidos en el sumario general del cargo y data sin que representaran un ingreso o gasto efectivo.

En este contexto, los cortes y tanteos debían diferenciar de manera estricta lo cobrado, lo pagado y lo debido cobrar, así como la existencia efectiva de la caja discriminada por ramos y sin mezclarlos en el ingreso de cada uno. Por otra parte, los tanteos debían tener un estricto orden: se iniciaba con la existencia del año anterior en caudales y especie, diferenciando el ramo al cual pertenecían; enseguida se expresaba ramo a ramo en el encabezado de cada uno lo debido cobrar para luego consignar cada partida de lo cobrado, registrando en una única columnilla lo efectivamente cobrado, mientras que el débito quedaba expresado en el párrafo final de cada ramo. Además de esto, cada rubro debía contener la expresión de la razón u ordenanza que daba sustento a su cobro, operación que se repetía para los libramientos y ramos de gasto (Sánchez, 2019).

${ }^{1}$ Colonia, Miscelánea, t. 83, documento 14, Archivo General de la Nación-Colombia (en adelante AGN-C).

${ }^{2}$ Colonia, Civil, Contaduría, documento 124, Archivo Central del Cauca, Colombia (en adelante ACC). 
Nuestras indagaciones han permitido constatar que la instrucción de Ortiz tuvo una aplicación parcial y bastante particular en el Nuevo Reino de Granada, tal y como lo demuestra su atenta observación en Cartagena de Indias y el reclamo de su instauración en 1781 por parte del visitador Gutiérrez de Piñeres (McFarlane, 1997, p. 320; Phelan, 1980, p. 44). Frente al caso de Cartagena, la orden fue puntualmente seguida; tal y como lo demuestra el propio Ortiz de Landázuri en una carta enviada a los oficiales reales de esta caja, aunque no emplean la acepción de corte y tanteo, sino la de estado general, así como no citan la instrucción para su elaboración, a la cual se apegaron para su cumplimiento, tal y como lo expresó el mismo Ortiz de Landázuri:

El estado general que remite es correspondiente al cargo y data de aquella caja y comprehensivo a todo el año de 1766, reconociéndose formado con tanta individualidad en sus partidas que no queda duda alguna en los ramos, y efectos que integran el erario, ni de las causas, y motivos en cuya virtud se hacen los pagos, y se puede con toda propiedad asegurar es un verdadero principio a tomar conocimiento del estado de la Real Hacienda de aquella caja, de que se ha carecido hasta ahora, y su método es conforme a la instrucción que se tiene dada, y que debe adaptarse en las demás de aquel reino, no sólo por el hecho de contener en sus partidas de cargo y data, toda la expresión requisita a verificar la certeza en fuerza de los documentos a que se refiere, sino también por la concordancia que al fin hacen los empeños de la Real Hacienda con los ramos que son acreedores según las anticipaciones que le hicieron en casos urgentes, y de la mayor importancia al real servicio. Aunque en el referido estado, se omite la expresión de haberlo formado con arreglo a la instrucción práctica que formó esta contaduría general en 18 de julio de 1766, y que para su observancia en los tanteos y cortes de caja de la América, se remitió generalmente de orden de S. M. a los virreyes, gobernadores y oficiales reales; es preciso sentar que es efecto propio de las reglas, y circunstancias que se contienen en la mencionada instrucción y un verdadero trasunto de ellas, de los fines que en él se indicaron, respecto de que después de manifestar el pormenor de cada uno de los ramos que en dicho año de 1766 integraron los 845 522 pesos del cargo y 422888 , la data; liquida el alcance y existencia que resultó del enunciado año que fueron 422633 pesos, y hace demostración de lo que pertenece a cada uno de los ramos de que se compone el estado general, que solo en darle este nombre, y no el de tanteo, varía con la instrucción [sic] $\left.\right|^{3}$

A pesar de este buen comienzo, en 1781 el visitador regente Gutiérrez de Piñeres envió a los oficiales reales de las distintas cajas expresas órdenes para que efectuaran los cortes y tanteos con arreglo a la instrucción, debido a su no cumplimiento (Friede, 1981, p. 1024). Igualmente, en 1796 el virrey Ezpeleta clamaba por la promulgación de instrucciones para la realización de las diligencias de corte y tanteo, lo cual hace sospechar su inobservancia (Ezpeleta, 1989, p. 272).

La instrucción práctica tuvo un impacto diferencial en cada territorio y una aplicación particular (tal y como será observado en el siguiente apartado para el caso de la caja matriz de Santafé). Por el momento es preciso observar cómo de la elaboración de cortes de caja se pasó a la composición de estados generales de ingreso y egreso a través de formularios, los cuales implicaron un grado mucho mayor de uniformidad. Los pedidos para el puntual envío de las cuentas con destino al Tribunal Mayor y a la Secretaría de Indias no cesaron; sin embargo, las exigencias seguían con

${ }^{3}$ Santa Fe, 1096, AGI. 
precisión los deberes expuestos por Ortiz de Landázuri por lo menos hasta 1781, pues para 1783 se iniciaría un nuevo proceso de trasformación de la metodología para rendir informes contables. Antes de abordar esta nueva trasformación, es necesario mencionar los requerimientos establecidos para la construcción de cuentas y el manejo de libros, los cuales también se vieron afectados poco después de la instrucción práctica de cortes y tanteos de 1766.

El 3 de septiembre de 1767 se publicó la nueva instrucción práctica para la formación de cuentas, las cuales debían contener la discriminación de los cargos y datas por clases e iniciar con lo no cobrado el año anterior, suma que se registraba en el cargo del año en cuestión y que se encontraba en la data del precedente. Después se registraba cada ramo con el nombre de su responsable, el periodo registrado, las leyes que amparaban la exacción del impuesto y la anotación de cada partida. Las datas también debían separarse por clase, siendo la primera el alcance del año anterior, y después se anotaba cada rubro en pliego separado dando cuenta de las libranzas y las reales órdenes que habían dispuesto su pago. Por último, cada una debía incluir un resumen en el que se registraba la sumatoria de los ramos. ${ }^{4}$ Dicha instrucción obligó a los contadores del Tribunal Mayor a redactar otras con particularidad a cada una de las cajas (Maqueda, 2007, pp. 655-671) y, como lo hemos podido constatar, se cumplió en la mayor parte de las mismas. Posterior a ello, en 1784 la nueva instrucción de Machado Fiesco estableció el manejo de tres libros: el manual, el de caja, y el mayor, cuyas características fueron:

Este método es conforme a la buena cuenta, y el que las leyes disponen; y, según él, se ha de tener por principio general, sin excepción, que toda partida pide dos asientos además del Libro Manual: uno en el de caja para la especie en que se cobra el adeudo, o para el deudor si es que se deja de cobrar; y otro en el mayor para el ramo a quien pertenece la cantidad adeudada. Lo propio sucede al pagar alguna cantidad por sueldo o gasto, pues necesita un asiento en el ramo o gasto o por cuya cuenta se paga, y otro en la especie que se da en pago; y lo mismo cuando se cobra lo que se asentó como deuda, pues necesita uno en la cuenta de la especie que se recibe en pago, y otro en la del deudos o deudores que la pagan; y acontece lo propio cuando se compra o vende alguna cosa, pues la que entra pide asiento de cargo, y la que sale por ella le pide data $[\mathrm{sic}] \mathrm{S}^{5}$

Así, desaparecía la partida simple de cargo y data por la doble de debe y haber, registrándose en la primera lo que ingresa y "Aquel a quien, o por cuya cuenta se paga, da o remite alguna cosa" [sic] (Donoso, 2010, p. 153), mientras que al haber irían lo que sale y "Aquel por cuya cuenta se recibe, o debe cobrar" [sic] (Donoso, 2010, p. 153). El registro debía seguir un orden lógico: primero se anotaban las transacciones en el manual en orden cronológico, luego se pasaba al mayor, discriminado por ramos y haciendo expresa mención de las hojas del manual en el cual se sustentaban las partidas y, por último, al de caja cuando el cobro o pago se hacía efectivo (Donoso, 2010, p. 24). Además de ello, la ordenanza estableció la división de los ramos con arreglo a su destino en comunes, particulares y ajenos: "Entre los ramos de ingreso hay unos que son de la

\footnotetext{
${ }^{4}$ Santa Fe, 778, AGI.

5 Tomado de Donoso (2010, p. 152), donde se incluye copia facsimilar de la Instrucción práctica y provisional en forma de advertencias, que debe servir a todas las cajas reales, o tesorerías, principales y foráneas de las Indias, para el modo de llevar las cuentas de la Real Hacienda entre año, de formar estados mensuales y tanteos anuales, y de dar cuenta general en fin de cada uno como está mandado: dispuesta por la Contaduría General y aprobada por el rey en 9 de mayo de 1784, elaborada por Machado Fiesco.
} 
Real Hacienda: otros que, aunque son de ella, deben reputarse como distintos y separados, porque sus fondos no deban invertirse en Indias, o estén precisamente destinados a algún particular objeto con expresa exclusiva de los demás gastos y cargas generales de Real Hacienda; y otros que son particulares y ajenos de ella" [sic] (Donoso, 2010, p. 158).

En Nueva Granada fue conocida la nueva instrucción, sin embargo, las múltiples dificultades para su aplicación obligaron a volver al método de partida simple de cargo y data, aunque manteniendo el uso de libros manuales y la separación de ramos entre comunes, particulares y ajenos, tal y como lo establecía la real orden del 25 de octubre de 1787 (Pérez y López, 1796, pp. 61-63).

Y aunque seguía vigente la preocupación en la metrópoli por conocer el verdadero estado de la Real Hacienda en el virreinato de Nueva Granada, y como producto de los desmanes de la guerra de independencia de Estados Unidos de América y las demandas que el conflicto implicó al interior del virreinato -agravadas por la rebelión de los comuneros-, el virrey se vio obligado a pedir auxilios a Nueva España, alertando a las autoridades metropolitanas quienes emitieron la real orden del 29 de octubre de 1783 :

Se ha enterado el Rey con mucha satisfacción de lo que ve expone en carta N 189 de treinta de abril último, dando cuenta de no haberse facilitado el auxilio de quinientos mil pesos que el antecesor de vuestra excelencia pidió al virrey de Nueva España y asegurando haberse cumplido sin él todas las obligaciones respectivas a los dominios de este virreinato, lo que manifiesta con evidencia la suma vigilancia, y acertadas disposiciones de ve para no empeñar más el erario. Para que su majestad se halle con seguras noticias del estado de su Real Hacienda quiere que ve remita con la posible brevedad un estado individual y exacto de todas las cargas anuales, débitos, créditos y valores del real erario de ese virreinato, expresándose por menor todos los productos con distinción de clases y cajas reales de modo que se venga en cabal conocimiento de lo que se debe a su majestad hasta fin del corriente año, créditos de la Real Hacienda a favor de particulares, cargas anuales con que se halla, el líquido producto anual con que debe contarse después de satisfechos todos los gastos que son precisos e indispensables, incluyendo las rentas reales estancadas, y todo lo demás respectivo al real haber, para formar un cabal juicio de su estado en este virreinato[sic].7]

Pese a ello, para 1787 aún no se tenía noticia de que la tarea hubiese sido llevada a cabo, como lo demuestra una nueva real orden emitida el 31 de julio de dicho año, en donde de nuevo se pedía que los oficiales dieran cuenta del estado de los cobros, gastos y débitos de la Real Hacienda 8

Aunque esta demora puede adjudicarse a la ineficiencia de los funcionarios de la corona en el virreinato de Nueva Ganada, lo cierto es que ella se debía al complejo trabajo de formación de instrucciones aplicadas a la realidad del entorno para construir los estados solicitados. Este

\footnotetext{
${ }^{6}$ Como producto del inicio de la guerra contra Inglaterra el virrey Flórez migró con destino a Cartagena dejando encargado de la Superintendencia de Real Hacienda del virreinato al visitador Gutiérrez de Piñeres, quien en aplicación de las disposiciones reales emitió las órdenes correspondientes para la toma de fondos de depósitos censo, los cuales serían redimidos con los productos de la renta de tabacos, así como para la recaudación del donativo de 1781. Estas medidas, junto con la aplicación de los nuevos reglamentos para el manejo de las rentas estancadas y las alcabalas, fueron factores determinantes para la explosión de la revuelta comunera que afectó el orden interno y por tanto el nivel de recaudo de los fondos extraordinarios para afrontar la guerra contra Inglaterra entre 1781 y 1782 . Véanse Phelan (1980) y McFarlane (2007).

${ }^{7}$ Colonia, Real Hacienda, t. 21, AGN-C.

${ }^{8}$ Colonia, Real Hacienda, t. 21, AGN-C.
} 
proceso culminaría con tres sendas instrucciones para la elaboración de los estados: los apuntes generales (del cual desafortunadamente desconocemos su contenido), los apuntes particulares para la formación de estados con aplicación a Quito, y los apuntes para la formación de estados de Santafé. Proceso que fue expuesto por los contadores del Tribunal Mayor de Cuentas de Santafé al virrey en comunicación del 1 de abril de 1788, en la cual justifican las causas de su retraso.9

Los apuntes particulares para la realización de estados generales de ingreso y egreso para la audiencia de Quito fueron redactados el 30 de julio de 1787 y remitidos a todas las cajas del virreinato. En ellos se ordenaba a los oficiales reales distinguir o separar los ramos de tributos y cruzada, se definía el débito corriente como referente a lo no cobrado en el año objeto de la cuenta, y se pedía registrar los créditos contra la Real Hacienda. Con base en estas aclaraciones los oficiales debían llenar un formulario en donde se listaban todos y cada uno de los ramos de ingreso y gasto, haciendo clara diferencia de sus valores (ingreso efectivo), pensiones (gasto efectivo por cada ramo), débitos atrasados, débito corriente y réditos a juro, además de que los gastos generales que no pertenecían a un ramo específico debían listarse bajo la denominación de masa común (véase figura 1).

Pero la finalidad de la orden no era sólo hacer un estado particular de cada caja, sino uno universal que diera cuenta de la totalidad del distrito del Tribunal de Cuentas de Santafé, razón por la que esta instancia se dio a la tarea de puntualizar y adaptar a cada caja los apuntes particulares diseñados para Quito, lo que produjo la redacción de los “Apuntes particulares concernientes al Distrito del Tribunal Mayor de Cuentas de Santafé, para la formación del estado universal de la Real Hacienda de su virreinato conforme a la real orden de 29 de octubre de 1783" (Mora, 1983). En este documento las instrucciones son muchos más claras y apuntan a simplificar la comprensión de los cuadros a través de la agregación de ramos, que, aunque separados en los libros y cortes de caja, era menester agrupar para dar una noción más expedita del estado de la Real Hacienda.

En tal sentido se pedía unir: $a$ ) bajo la denominación de Alcabalas los ramos de almojarifazgo de entrada de géneros de la tierra, géneros y frutos del país, nuevo impuesto, unión de las armas, embarque y puertos, Armada de Barlovento, sisa, puertos, real proyecto, derechos de salida, y almojarifazgo de puestos; $b$ ) bajo la de tributos y vacantes los ramos de demoras, requintos y vacantes de encomiendas, todas sus especies reducidas a pesos plata; $c$ ) bajo la de oficios vendibles los ramos de almotacén y contraste; $d$ ) de medias anatas reales y seculares los ramos de emolumentos, conducción y servicio pecuniario; $e$ ) de quintos todos los que fuesen cobrados sin distinción de metales; $f$ ) bajo la de composición de tierras los ramos de censos, donativos, alquiler de edificios, arrendamiento de casa de campo, y represalia a la nación inglesa, y $g$ ) bajo la denominación de almojarifazgo todos los ramos por el comercio externo sin distinción de derechos de entrada y salida, los de introducción de negros y la extracción de caudales y, por último, los fletes y los derechos de piso debían estar unidos, así como los derechos de fundición y ensaye.

Igualmente se ordenó separar las vacantes mayores, menores y el noveno, así como las medias anatas seculares y eclesiásticas. Estos estados no incluyen los productos de las rentas estancadas pues su administración dependía de la dirección general de la mismas -instancia que hacía las veces de tribunal independiente en la materia-, así como se debían clarificar las remisiones de otras tesorerías con distinción de los ramos de los que provenían. El resultado no deja de ser más que sorprendente pues el Tribunal Mayor de Cuentas logró construir para el año de 1783 un estado de los valores, pensiones fijas, débitos atrasados y juros en contra de todas y cada una de

${ }^{9}$ Archivo Anexo II, Real Hacienda, caja 158, carpeta III, AGN-C. 
FIGURA 1. MODELO EMPLEADO PARA LA ELABORACIÓN DEL ESTADO DE LA REAL HACIENDA DE LA TESORERÍA DE QUITO

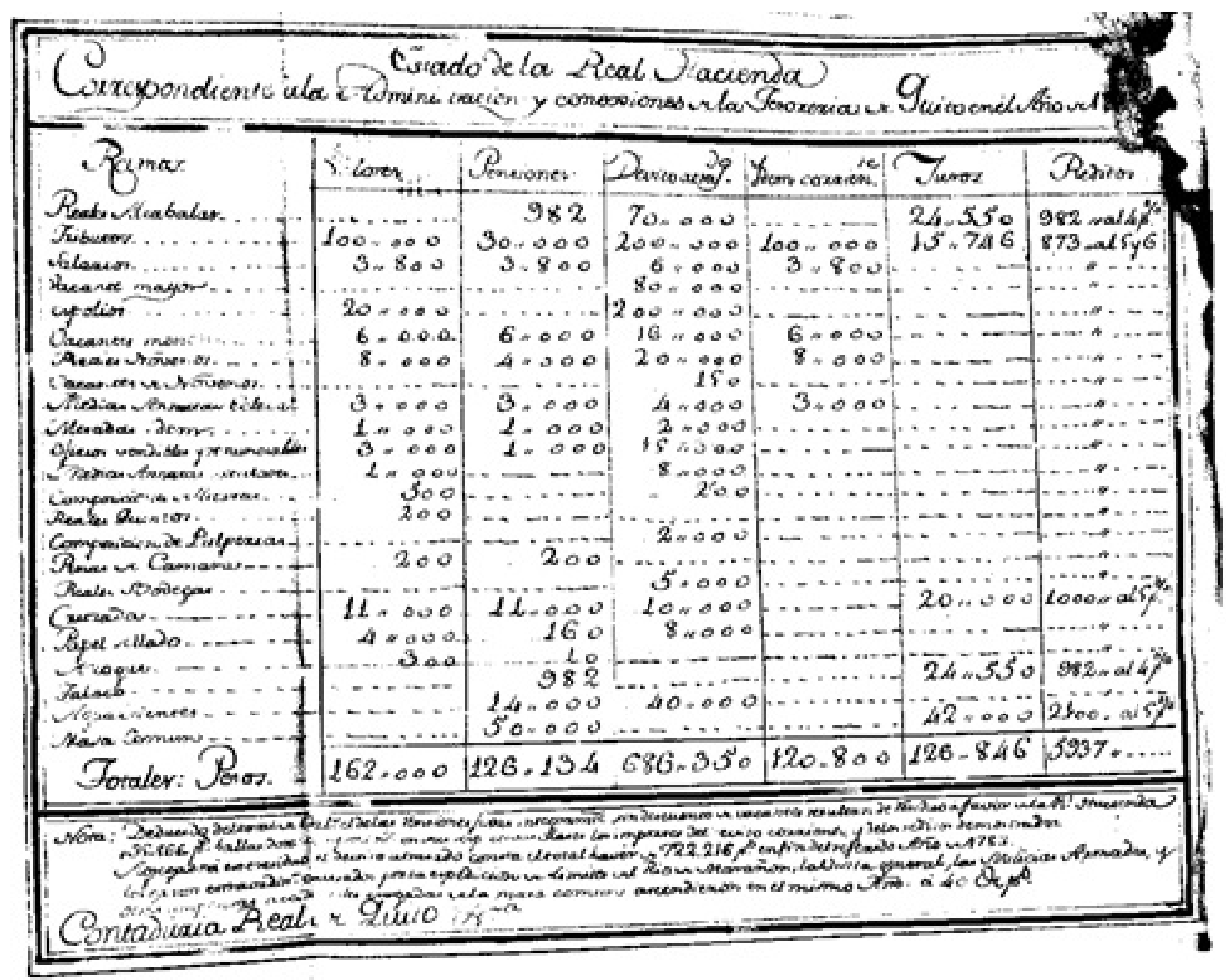

Nota: incluido en los apuntes particulares para la formación del estado general de la Real Hacienda del Distrito del Tribunal de Cuentas de Quito conforme a la real orden del 29 de octubre de 1783.

Fuente: Colonia, Real Hacienda, Cartas, caja 33, AGN-C.

las tesorerías bajo su jurisdicción, incluyendo las de las administraciones de rentas estancadas y las pertenecientes al Tribunal de Cuentas de Quito (Mora, 1983), ejercicio que sería repetido en 1789 (Durán y Díaz, 2013).

Sin embargo, los avances no se frenaron allí, de nuevo una real orden, expedida el 21 de junio de 1791, daría pie para la elaboración de una completa relación del estado de la Real Hacienda, ahora las autoridades metropolitanas requerían una relación exacta de los ramos propios estableciendo su importancia, su modo de recaudo, el nombre de los encargados de ellas, su valor entero anual, el número de sus empleados, sus sueldos, los gastos de cada ramo, el producto de cada caja, el partido que comprenden las cajas matrices y la distancia y método para hacerse los enteros entre cada una de ellas ${ }^{10}$ Esta medida fue acogida por los oficiales de la Caja Real de Santafé quienes

${ }^{10}$ Colonia, Real Hacienda Cartas, caja 33, AGN-C. 
pudieron dar cabal cumplimiento a la orden, dando además una completa narración histórica del desarrollo de cada uno de los ramos ${ }^{11}$ y ofrecer un estado general de la Caja de Santafé respecto del año 1788 con arreglo a los preceptos de los apuntes particulares antes citados.

Posterior a ello, de nuevo por disposiciones reales se emprendió la última reforma al modo de informar sobre el estado de la Real Hacienda en el virreinato de Nueva Granada previo al estallido independentista. Pedro López de Lerena, quien para entonces se desempeñaba como secretario del despacho universal de Hacienda, remitió la nueva disposición del 12 de junio de 1791 debido a que los anteriores estados reportaban los valores, pensiones, débitos, productos y deudas en cuadros separados y sin distinción de ramos propios, particulares y ajenos, como se había establecido en la instrucción de Machado Fiesco de 1784, de la cual se había conservado tal diferenciación como lo expresó la real orden del 25 de octubre de 1787 (Pérez y López, 1796, pp. 61-63). La orden de 1791 expresaba:

Debiéndose componerse el producto total de todas las administraciones del virreinato en un solo estado, incluyendo en el todos los ramos de la Real Hacienda con distinción de los que son propios de ella, y de los que se compone ese erario, de aquellos que aunque lo sean tienen precisa aplicación, dispondrá vuestra excelencia como se lo prevengo en la real orden, así se efectué, cuidando de que vengan anualmente en términos de que por ellas se pueda a una sola vista instruirse de los ramos de que se compone el erario de ese virreinato, los valores enteros de cada uno, sus gastos, sus sueldos fijos y el líquido producto de cada uno, anotándose los débitos activos y pasivos de la Real Hacienda, lo pagado a cuenta y cobrado de débitos atrasados y los que resulten en fin de cada año a favor y en contra [sic] 12

Orden a la que se adicionó la del 5 de julio de 1791, en la cual se reitera la necesidad de diferenciar ramos propios, particulares y ajenos, además de que se ordena anotar para cada ramo por casillas separadas los valores enteros, los gastos fijos y eventuales (causados en su manejo y recaudación), el líquido sobrante y lo no cobrado: ${ }^{13}$ disposición bajo la cual se compuso el modelo que sería empleado por las distintas cajas reales hasta previo el inicio de la crisis de la monarquía católica en 1808, así como por el Tribunal Mayor de Cuentas (véanse figuras 2 y 3).

Frente a los ramos particulares y ajenos la real orden del 5 de julio de 1791 hacía una aclaración puntual referida al registro de las remisiones de otras cajas, especificando al ramo que pertenecían, así como si ingresaban o salían de la caja en cuestión, agregando otra casilla para los alcances de cada uno de ellos (véase figura 3).

Este recorrido permitió observar cómo durante el siglo XVIII la instauración de una serie de reformas contables intentaba responder a la necesidad de información clara y de fácil comprensión para las autoridades metropolitanas, inmersas en una constante demanda de recursos para hacer frente a las obligaciones financieras que implicaba el mantenimiento del dominio imperial frente a los retos bélicos que le significaba la competencia frente a Inglaterra y Francia. Para las autoridades metropolitanas no era útil el empleo de los sumarios generales de cargo y data como registro fidedigno del estado de los ingresos y egresos de las cajas, ya que su remisión podía tomar años tras la revisión de las cuentas por parte de cada uno de los tribunales de cuentas, quienes

${ }^{11}$ Archivo Anexo I, Real Hacienda, t. 6, AGN-C.

${ }^{12}$ Colonia, Real Hacienda Cartas, caja 33, AGN-C.

${ }^{13}$ Colonia, Real Hacienda, Cartas, caja 28, AGN-C.

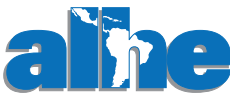


FIGURA 2. MODELO PARA EL REGISTRO DEL ESTADO

DE LOS RAMOS PROPIOS DE LA REAL HACIENDA

DE ACUERDO CON LA REAL ORDEN DEL 5 DE JULIO DE 1791

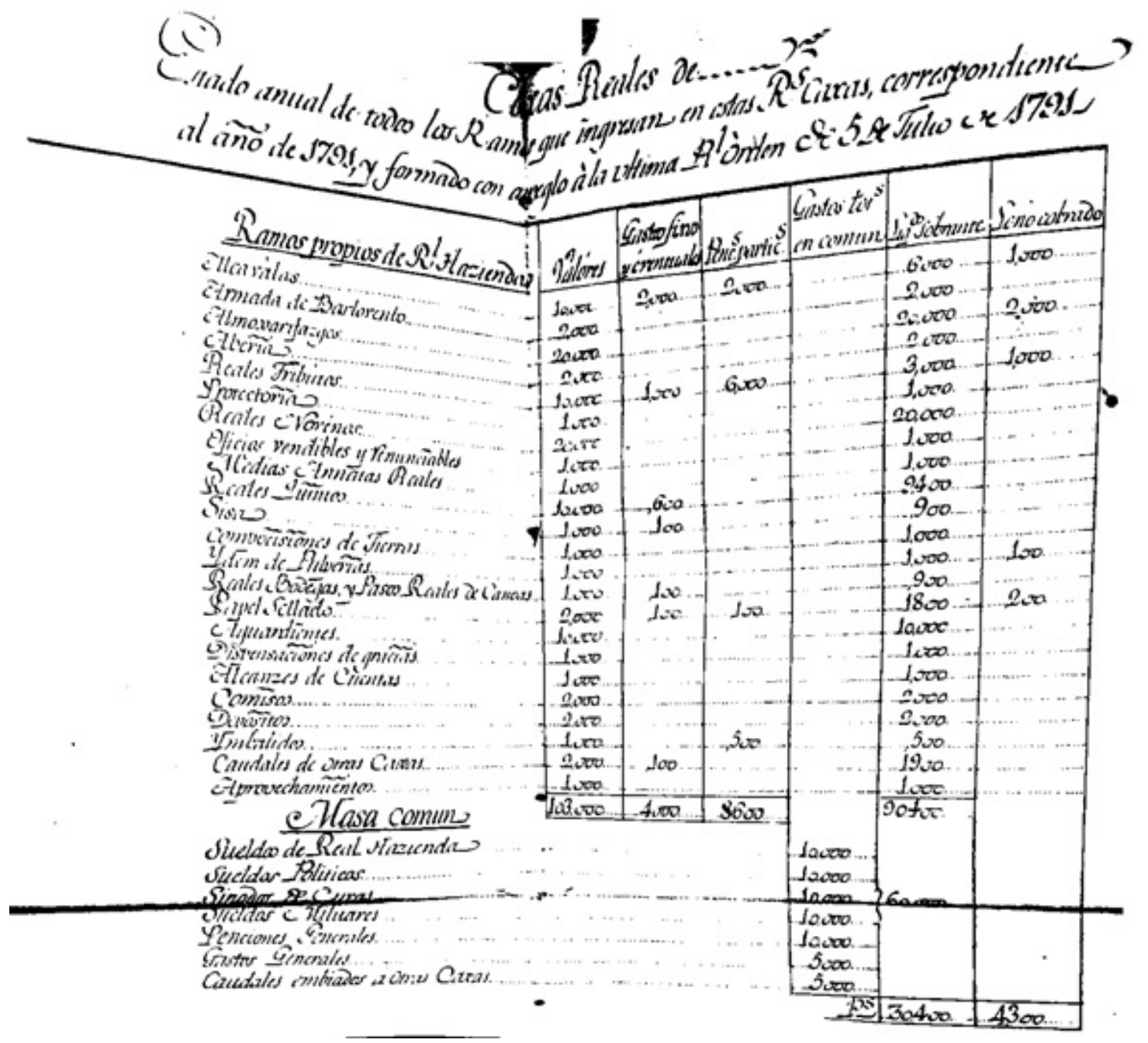

Fuente: Colonia, Civil, Contaduría, documento 165, ACC.

los cotejaban con arreglo a los libros como herramientas de control de los funcionarios de Real Hacienda (Sánchez, 2019), mientras que en la metrópoli se requerían de inmediato. Ante ello, se intentó uniformar la elaboración de las diligencias de corte y tanteo, la teneduría de libros, la aplicación de la partida doble, la diferenciación de ramos (propios, particulares y ajenos), así como poco a poco se fue perfeccionando la elaboración de estados generales de ingresos y egresos hasta la conformación de un modelo uniforme para todas las cajas del distrito del Tribunal Mayor de Cuentas de Santafé. 


\section{FIGURA 3. MODELO PARA EL REGISTRO DEL ESTADO DE LOS RAMOS PARTICULARES Y AJENOS DE LA REAL HACIENDA DE ACUERDO CON LA REAL ORDEN DE 5 DE JULIO DE 1791}

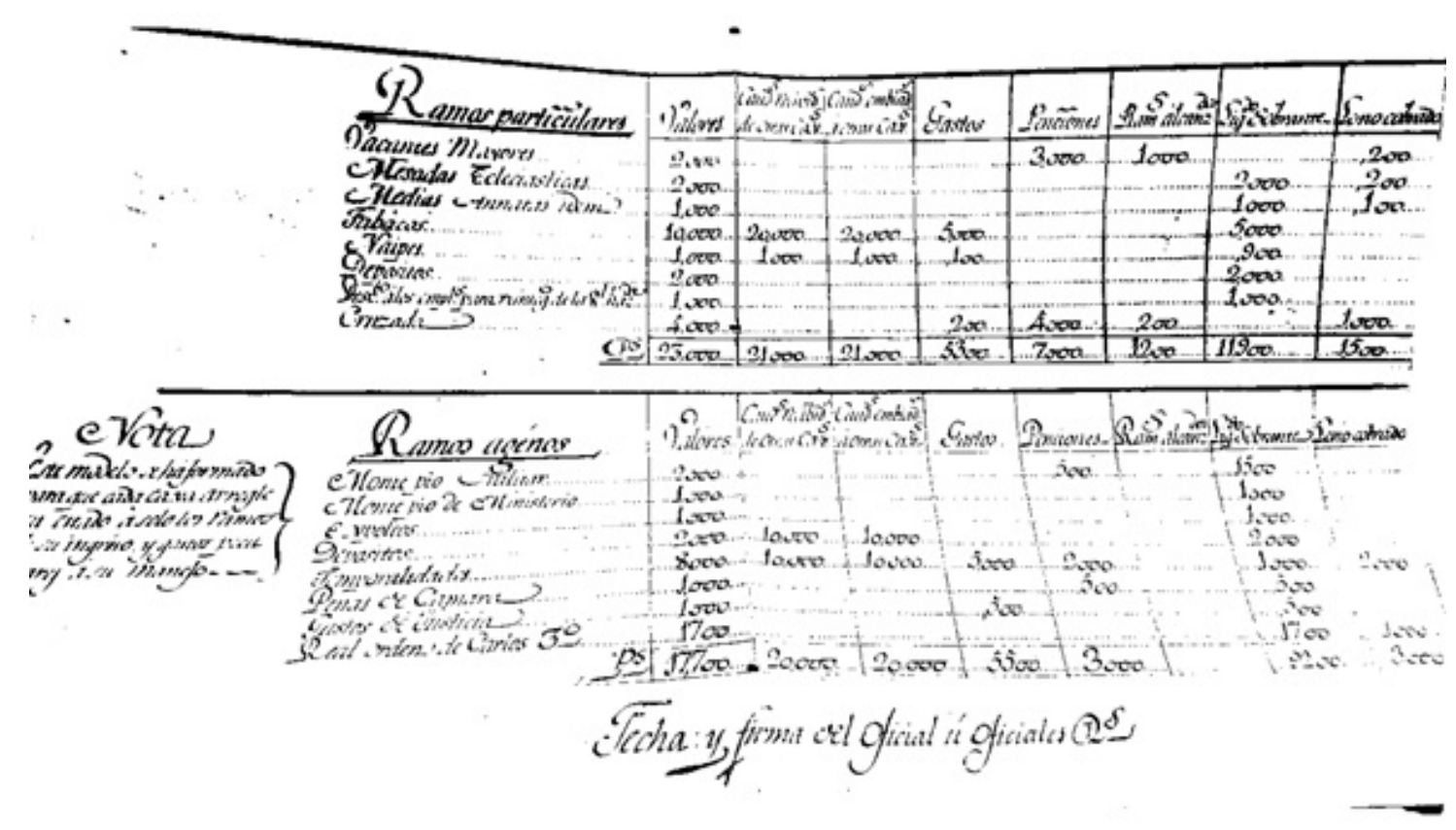

Fuente: Colonia, Civil, Contaduría, documento 165, ACC.

El resultado obvio de cada ejercicio fue la elaboración de diversas cuentas, las cuales se convierten en las herramientas que actualmente los historiadores emplean para dar un vistazo a los procesos de sostenimiento del Estado o al sector real de la economía. Basados en la discusión del primer apartado y del recorrido presentado en la segunda, expondremos diversos tipos de cuentas que reportaron movimientos de la Caja Real de Santafé durante la segunda mitad del siglo xviII.

\section{Las guentas de la Caja Real de Santafé en la segunda mitad del siglo xviII}

El presente apartado da cuenta del impacto de las reformas contables para el registro de las operaciones del real erario en la caja matriz del virreinato de Nueva Granada. Para tal fin hemos decidido emplear cinco tipos documentales: un libro común, un estado general de ingreso y gasto previo al uso de los formularios diseñados en 1791, un estado de la deuda, una diligencia de corte y tanteo, y un sumario de cargo extractado de los libros comunes. Para ello compararemos los cinco primeros tipos documentales en un mismo año (1778) y posteriormente expondremos las características de uno de los cuadros generales de ingreso y egreso elaborado para 1791. Todo lo anterior pretende dar claridad sobre las razones de las diferencias de los resultados cuantitativos de diversas investigaciones y que se discutieron en el primer apartado, así como determinar qué documentos son más fiables a la hora de dar cuenta del ingreso, gasto y deuda a favor y en contra de la Caja Real durante la segunda mitad del siglo xviII. 
En primera instancia nos ocuparemos del sumario general de cargo perteneciente a 1778 , ya que es con base en este tipo documental que se han realizado las investigaciones que arrojan datos cuantitativos sobre la Caja Real de Santafé. Recordemos que este se trata del resumen de cada uno de los pliegos en donde se consignan los ramos de cargo en el libro común. El sumario inicia con la existencia del año anterior sin especificar su especie u origen, enseguida hace referencia a las remisiones que distintas cajas hicieron con destino a Santafé, destacando el pliego del libro mayor al cual corresponde cada una, después lo hace con cada uno de los ramos y cierra con la sumatoria total que asciende a 482447 pesos ${ }^{14}$

El libro común de cargo de $1778^{15}$ inicia con la especificación de la existencia en especies, continúa con el debido cobrar de 1777 dando cuenta del origen de los adeudos, más adelante da cuenta de cada una de las remisiones por cada caja y continúa con cada uno de los ramos. En cada pliego se específica el nombre de los encargados, las razones y ordenanzas que legitiman el cobro de los derechos, y en cada una de las partidas se da cuenta de la fecha y los datos de quienes hicieron el pago. Sin embargo, aquí aparece ya una clara diferencia frente al sumario, pues en el ramo de alcabalas reporta un total de 32733 pesos, los cuales coinciden con el total del libro, pero después de haberle sumado lo debido cobrar en 1778, que ascendió a 1591 pesos, incluidos en la última partida del libro común, por lo que lo efectivamente ingresado fue 31142 pesos. Ello se repite en varios ramos (véase cuadro 1 ).

Este sencillo ejercicio deja claro que si buscamos dar cuenta de lo efectivamente ingresado en la Caja Real de Santafé los sumarios de cargo y data no son la mejor fuente, pues registran cantidades que no hacen referencia al recaudo efectivo, ello es lógico si se toma en cuenta que la fuente de la que nacen (libros comunes) son una herramienta de control de las labores de los oficiales mayores; su finalidad nunca fue la de reportar a la corona el estado de las cajas, para ello sería preciso cotejar cada uno de los libros comunes y hacer un total escrutinio de cada partida (Sánchez, 2013). Esta constatación dificultaría en gran medida el uso de tales documentos para determinación del nivel de recaudo y gasto efectivo. Sin embargo, como se expuso en el apartado anterior, el gobierno metropolitano era consciente de tal situación, de allí que ordenara la elaboración de otros tipos documentales como los cortes de caja, los estados generales y los estados de deuda, los cuales reposan con gran sistematicidad entre 1769 y 1785 para la Caja de Santafé en el Archivo General de Indias. Y serán analizados a continuación para determinar hasta qué punto reportan el estado del recaudo y el gasto efectivo de la tesorería.

Los encargados de la caja de Santafé, como todos los de los dominios de la corona española al comienzo de cada año, estaban obligados a la formación del tanteo de la caja. En la diligencia de 1778 de la Caja Real de Santafé se expresa -después de su encabezado- lo sobrante del año en cuestión, tanto en moneda como en especie, y enseguida ofrece el pormenorizado recuento de los pagos efectuados dando cuenta de su destino y del ramo al cual pertenecen, especificando el número de libranzas expedidas. Finalmente, registran el total de la data y clarifican qué parte de la suma de ella pertenece a las existencias que se han agregado. Para 1778 se encuentra una data total de 400564 pesos, de los cuales 24556 son sobrantes y 400744 de lo librado efectivamente. La diligencia continúa con el registro de los cargos de 1778 iniciando con la existencia de 1777 expresada en caudales y especies discriminada por ramos, enseguida se da cuenta de las remisiones de cada una de las cajas y el ingreso por cada uno de los ramos, cada uno de los registros cita las

${ }^{14}$ John Jay TePaske Papers, 1500s-1988, caja 3, carpetas 1 y 2 .

${ }^{15}$ Santa Fe, 778, AGI. 


\section{CUADRO 1. COMPARATIVO DEL REGISTRO DEL CARGO EN EL LIBRO COMÚN Y EL SUMARIO GENERAL DE LA CAJA DE SANTAFÉ EN 1778 (EN PESOS)}

\begin{tabular}{lrrr}
\hline Ramos & $\begin{array}{c}\text { Efectivamente } \\
\text { ingresado }\end{array}$ & $\begin{array}{c}\text { Debido cobrar } \\
\text { (1778) }\end{array}$ & $\begin{array}{r}\text { Registrado en el } \\
\text { sumario de cargo }\end{array}$ \\
\hline Oficios & 4392 & 1814 & 6207 \\
Demoras y requintos & 13310 & 2223 & 15533 \\
Aguardiente & 77398 & 5800 & 83999 \\
Arrendamiento de tierras & 1739 & 944 & 2684 \\
\hline
\end{tabular}

Fuente: John Jay TePaske Papers, 1500s-1988, caja 3, carpetas 1 y 2.

hojas del Libro Real Común en el cual se encuentran consignadas; por último, se totaliza el cargo en 400919 pesos, y restando la data queda un alcance a favor de la Caja Real de 265 pesos. El documento concluye con la reiteración del cargo, la data y el alcance, y aclara que el último valor tiene la condición de provisional hasta tanto no se haga la revisión de la cuenta de manera detallada 16

Terminado el tanteo, la revisión de la cuenta continuaba con la formación del estado de la deuda, en este se registran cada una de las deudas de años anteriores y de 1778, especificando el libro en el cual se encuentran consignadas, los ramos a los que pertenecen, los deudores, los pagos que han sido efectuados (si los hubiere) y el saldo restante; por último, se totaliza la sumatoria de las deudas que para dicho año llegaron a 40167 pesos. Después de establecidas las deudas los oficiales se encargaban de producir un nuevo documento titulado "Estado general de la caja", fruto de la real orden del 11 de marzo de 1765. Antes de dar cuenta de su contenido para 1778, es importante conocer los antecedentes de su elaboración. 17

Para 1769, en cumplimiento de la real orden del 11 de marzo de 1765, los oficiales de la Caja de Santafé enviaron el estado general de la caja, la relación de deuda y de ingresos por diezmos a la Contaduría de Indias, sin embargo, ellas estuvieron cargadas de defectos, hecho reconocido por el contador Ortiz de Landázuri quien lo expuso al Consejo de Indias en los siguientes términos:

Además de encontrarse formadas las dichas tres relaciones sin algún método regular, claridad, y expresión, se advierte en ellas, entre otros muchos defectos, el de no explicarse los gastos, dispendios, o cargos a que se hallan afectas las reales cajas de Santafé, cuyo particular se mandó contuviesen dichas relaciones por la mencionada real orden y que asimismo dicen los oficiales reales que para la correspondiente a los valores de diezmos, se vieron precisados a solicitar noticias de su importe al contador del cabildo, dando cuenta de las dificultades que ocurrieron a este para su contestación y con que se acredita la ninguna formalidad y absoluta inobservancia de las leyes con que los referidos oficiales reales aplican al desempeño de sus empleos, pues deben asistir a

\footnotetext{
${ }^{16}$ Santa Fe, 784, AGI.
}

${ }^{17}$ Santa Fe, 784, AGI. 
las almonedas de rentas y remate de diezmos, teniendo razón puntual en sus libros de todos estos particulares para el cobro y recaudación de los reales novenos y para otros muchos fines del real servicio 18

De inmediato Ortiz solicitó al virrey de Nueva Granada nuevas relaciones con expresión de los gastos, lo que permitió que poco tiempo después se remitiesen las relaciones y estados de caja corregidos para los años que corren entre 1765 y 1770, mismos que cumplieron a cabalidad con las especificaciones, tal y como se lo escribió Ortiz de Landázuri al Consejo de Indias en carta de 14 de enero de 1771:

La contaduría general enterada del contexto de los referidos tres testimonios y de la menuda expresión que hace en cada una de las respectivas partidas del cargo y data del comprensivo estado general de la Real Caja de Santafé, tiene por conveniente hacer presente a la superior justificación del consejo que por la última real cédula del $11 \mathrm{de}$ marzo de 1765, se mandó a los oficiales reales de Santafé que remitiesen una relación clara y distinta de todos los ramos de que se compone el real erario en aquel virreinato, y de las cargas, quiebras, o descubiertos que sobre sí tenían para providenciar lo conveniente, y a su consecuencia le dan los ministros en los adjuntos testimonios, con tanta individualidad, que en su narrativa de mucha importancia, pues por ella en cualquier momento en que convenga a sM o al Consejo saber el ingreso de la caja de Santafé y el de las remesas hechas por las demás sufragáneas sujetas a aquel virreinato, se puede suministrar prontamente con la puntualidad correspondiente, sin que para la resolución haya necesidad de ocurrir por otras noticias a la América ni guardar las consiguientes resultas $[\mathrm{sic}]$

De esta manera se instituyó la elaboración de los estados de caja después de efectuado el corte y tanteo, así como la relación de las deudas, documento cuyo fin fue expresar los ingresos, egresos, deudas en contra y debido cobrar de la Caja Real de Santafé, tipo documental que para 1778 se encabeza de la siguiente forma:

Don Manuel de Revilla, contador propietario y don Santiago Brun, tesorero interino, oficiales reales de las reales cajas matrices de la ciudad del Nuevo Reino de Granada, habiéndose cumplido con el corte y tanteo, de estas reales cajas, relativo al año próximo pasado de 1778 y con la relación general de todas las deudas causadas hasta su final, uno y otro con arreglo a las leyes, ordenanzas y últimas reales cedulas pasamos a formar la relación del estado de estas cajas, según se nos tiene preceptuado por su majestad de once de marzo de mil setecientos sesenta y cinco, con distinción de todos los ramos de Real Hacienda y de los pagamentos hechos según lo que consta por el libro real común y los de ramos particulares e individualmente por el de libramientos respectivo al referido año. Dirigiendo a su majestad un ejemplar de este estado y otro al real y supremo Consejo de las Indias como se nos manda y el tenor de él es la forma siguiente [sic] 20

${ }^{18}$ Santa Fe, 783, AGI.

${ }^{19}$ Santa Fe, 784, AGI.

${ }^{20}$ Santa Fe, 784, AGI. 
El estado inicia con el cargo de 1778, teniendo como partida primera la existencia al fin del año anterior, aunque sólo registrado en moneda, enseguida se da cuenta de cada una de las remisiones de cada caja subalterna y de todos y cada uno de los ramos de recaudo, especificando las hojas en que se contienen las particularidades de cada uno en el libro común. Respecto a las datas, estas eran registradas discriminando el tipo de gastos que representaban, el número de libranzas que fueron giradas, especificando los funcionarios o instituciones a las cuales se cancelaban sueldos o los ramos por los cuales se consignan diversas pensiones. Estos estados concluían con una aclaración muy significativa respecto del cargo y la data general (véase cuadro 2).

Esta aclaración también deja sentado que todo lo debido cobrar para 1778 se incorporó como parte integrante del cargo de cada uno de los ramos en el libro común, por tanto están insertos en el sumario general, razón por la cual este último documento no reporta el ingreso efectivo en cada uno de ellos, mismo que sí se encuentra expresado tanto en los tanteos como en los estados de la caja, debido a que estos han sido separados en cuenta aparte en la relación de deuda, de tal forma que ambos nos dan un panorama diáfano de lo efectivamente recaudado y librado. Por último, los oficiales daban cuenta de los empeños que pesaban sobre la caja.

Si se observa el ingreso y el gasto de la Caja Real de Santafé es menester fundarse en la revisión de estos tres tipos documentales, los cuales aportan la información de cada uno de sus ramos sin débitos atrasados ni corrientes, ya que ello se encuentra especificado en la relación de deudas, ejercicio que es mucho más dispendioso con los sumarios generales de los libros comunes, pues implicaría revisar pliego por pliego de cada partida para sustraer del total de cada ramo lo debido cobrar. Este tipo documental a la postre evolucionaría en la década de 1790 para la realización de los cuadros de ingreso, egreso y deuda.

El modelo para la elaboración de estados generales (imágenes 2 y 3 ) fue aplicado de inmediato en Santafé, como lo registra el perteneciente a 1791 21 en donde puede encontrarse la siguiente información: para los ramos comunes: valores, gastos fijos y eventuales, pensiones particulares, gastos totales en común, líquido sobrante, y lo no cobrado; cada uno por columnas separadas. Todos y cada uno de los valores librados como producto de los gastos de la masa común, que incluyen: sueldos de Real Hacienda, sueldos políticos, sínodos de curas, sacristanes de ciudades, sueldos militares, pensiones generales, caudales enviados a otras cajas, así como principales, y réditos pagados. Para los ramos particulares y ajenos: valores, caudales recibidos de otras cajas, caudales enviados a otras cajas, gastos, pensiones, alcances, líquido sobrante, y lo no cobrado; cada uno por casillas separadas.

Este tipo de prácticas indudablemente son producto del proceso de reforma a la contabilidad de Indias emprendida por el contador Tomás Ortiz de Landázuri, las cuales se expresaron en la instrucción práctica para la realización de cortes y tanteos de 1766 y la instrucción práctica para la elaboración de cuentas de 1767. Si bien es cierto que tanto los estados o los tanteos de la Caja de Santafé no citan las razones para el cobro de los distintos gravámenes, así como tampoco expresan dichas razones para los libramientos, ambos tipos documentales sólo registran lo efectivamente recaudado y gastado, dando cuenta por separado del debido cobrar de años precedentes y del año de la cuenta en las relaciones de deuda, sin confundirlo en cada uno de los ramos como sí acontece en los sumarios generales de los libros comunes, dando cabal cumplimiento al principal objetivo de lo ordenado por Ortiz de Landázuri.

${ }^{21}$ Archivo Anexo II, Real Hacienda, caja 80, AGN-C. 


\section{GUADRO 2. EXPLICACIÓN DEL GARGO Y LA DATA GENERAL EN EL ESTADO DE INGRESOS, EGRESOS Y CARGAS DE LA CAJA REAL DE SANTAFÉ EN 1778}

\begin{tabular}{lr}
\hline Concepto & En pesos \\
\hline Cargo general & 482448 \\
Debido cobrar hasta 1777 y cobrado en 1778 & 41361 \\
Debido cobrar en 1778 & 40167 \\
Caudal sobrante en 1777 & 42948 \\
Caudales ingresados efectivamente & 357970 \\
Data general & 482182 \\
Debido cobrar hasta 1777 y cobrado en 1778 & 41361 \\
Debido cobrar en 1778 & 40167 \\
Caudales efectivamente librados & 376097 \\
Existencia a fin de 1778 & 24556 \\
\hline
\end{tabular}

Fuente: Santa Fe, 784, AGI.

Estos principios se mantuvieron a través de la consolidación de modelos para el registro de estados de ingreso y egreso que se describieron con anterioridad, pero también llegaron a ser parte de los sumarios generales de cargo y data de los libros comunes por los menos desde 1795, en donde empiezan a aparecer los ramos discriminados y frente a ellos dos columnas: una perteneciente a lo cobrado y otra a los débitos, lo que se replica en las datas apareciendo las columnas de lo pagado y el débito, distinto a lo que se hacía con anterioridad, en donde en una sola columna se anotaban las cantidades por cada ramo sin distinguir entre lo efectivamente recaudado y pagado, de lo no cobrado y debido pagar. En tal sentido, consideramos que un acercamiento más diáfano en términos cuantitativos al movimiento de la Caja de Santafé, y por ende de una aproximación a sus actividades productivas, así como de los mecanismos empleados por el gobierno para su sostenimiento, sólo es ofrecido por los tanteos, estados de ingreso y egreso, así como de las relaciones de deuda, mas no de los sumarios de cargo y data de los libros comunes, por lo menos previo a 1795, ejercicio que aún está por hacerse.

\section{Conclusiones}

Las disparidades cuantitativas de las series construidas para los registros del cargo y la data de la Caja Real de Santafé durante segunda mitad del siglo XviII, elaboradas en los dos trabajos que se ocupan de ella (Meisel, 2011a; Pinto, 2016), surgen de varios errores. Ambos asumen los sumarios generales de cargo y data como instrumentos que reportan el ingreso y egreso efectivo de la caja. También hacen una aplicación parcial del método de agrupación de ramos por actividades económicas propuesto por Klein (1973). Las dos investigaciones se han desarrollado sin tomar en cuenta la puntual comprensión de la lógica contable en la cual fueron elaboradas las cuentas.

Gracias a trabajos como los de Sánchez hemos podio comprender que en la lógica de la contabilidad diseñada desde la metrópoli para las Indias los cargos y las datas no son sinónimos de ingresos y egresos (Sánchez, 2013). De igual forma se ha podido constatar cómo los sumarios de 
cargo y data no tenían por finalidad reportar el ingreso y egreso efectivo, ya que se constituían en herramientas de control de las actividades de los oficiales reales, aquello de lo que se les hacía encargo o de lo que se descargaban -como parte de su cotidiano oficio-, universo que incluye las deudas por cobrar, las existencias o las remisiones de otras tesorerías (Sánchez, 2019). De este fenómeno no fue ajena la corona, razón por la cual se aprestó a componer una gran cantidad de reales órdenes e instrucciones que buscaban como principal objetivo lograr el acceso a información anual que diera cuenta del ingreso, egreso y debido cobrar de cada una de las tesorerías de una manera uniforme.

Nueva Granada no fue ajena a esta determinación, y como se pudo constatar en el segundo apartado de este trabajo, diversas instancias se dieron a la tarea de reformar las prácticas contables en su interior, reforma que se materializó en diversos tipos de manuales para la elaboración de cuentas, como las instrucciones prácticas de 1766 y 1767 -elaboradas por la Contaduría de Indias-, varias reales órdenes que desde el Ministerio de Hacienda de la Indias fueron enviadas al virrey, manuales como los apuntes generales y particulares para la elaboración de estados de ingreso y egreso construidos por el Tribunal Mayor de Cuentas, hasta llegar a consolidar modelos para tal fin desde 1783, consolidándose uno en 1791.

Como resultado, los encargados de la caja llegaron a elaborar con sistematicidad, entre $1769 \mathrm{y}$ 1785, los tanteos, estados de la caja y de deuda para posteriormente emplear los cuadros de estados generales y trasformar los sumarios de cargo y data desde 1795. Todos y cada uno de los tipos documentales citados logran ir más allá de los sumarios generales previos a 1795, cuyo principal defecto era consignar en la sumatoria de cada ramo las deudas por cobrar de años anteriores y del año de sus respectivas cuentas, lo que hace imposible su depuración a menos de que se revise partida por partida de los libros comunes.

En tal contexto, es preciso para futuros trabajos la construcción de series de ingreso y egreso a través de los tanteos, estados de la caja y de deuda, así como de los cuadros que reportan el estado general de la caja, ya que todos ellos distinguen lo efectivamente recaudado de los débitos atrasados y lo efectivamente gastado de lo adeudado. Igualmente, es preciso la elaboración de investigaciones que denoten el proceso de recepción, adaptación, resistencia y aplicación de cada una de las nuevas reformas implementadas en términos contables, tanto en la caja de la capital virreinal como para sus subalternas. En tal sentido, es imperioso desechar el uso de los sumarios de cargo y data si se busca tener un acercamiento de lo ingresado y gastado en cada caja, lo cual no implica la falta de utilidad de los libros de los cuales son tomados, ya que en conjunto, estos reportan significativos datos en torno a la identificación de los individuos inmiscuidos en la Real Hacienda, las transacciones diarias propias del ejercicio fiscal y las especies en las que se efectuaron las transacciones, piezas de incalculable valor para otro tipo de objetos de investigación que no sólo intenten construir series cuantitativas, sino ahondar en variables de orden cualitativo, así como para aquellos que busquen cotejar la validez de las cifras consignadas en otras fuentes.

\section{LISTA DE REFERENCIAS}

Arévalo, D. y Rodríguez, O. (2001). Gremios, reformas tributarias y administración de impuestos en Colombia. Bogotá: Universidad Externado de Colombia.

Arévalo, D. y Rodríguez, O. (2008). La fiscalidad bajo un régimen de dominación colonial: El caso de la Caja Real de Cartagena, 1738-1802. Anuario Colombiano de Historia Social y de la Cultura, 35, 19-64. Recuperado de https://revistas.unal.edu.co/ 
Bátiz-Lazo, B., Hernández, J. J., Maixé-Altés, J. C. y Nuñez, M. (2012). Adoption, diffusion and appropriation of double entry book-keeping in Mexico and Spain. América Latina en la Historia Económica, 19(3), 164. DOI: 10.18232/alhe.v19i3.532

Donoso, A. (1997). Estudio histórico de un intento de reforma en la contabilidad pública: La aplicación del método de la partida doble en las cajas reales de Indias (1784-1787). Revista Española de Financiación y Contabilidad, 26(93), 1045-1089.

Donoso, A. (2001). El virrey de Lima: Caballero de Croix. Defensor de la partida doble en el siglo XVIII. Revista Española de Financiación y Contabilidad, 30(107), 165-206. DOI: 10.1080/0210 2412.2001.10779416

Donoso, A. (2008). Organización y funcionamiento administrativo y contable de la Real Hacienda de Indias en tiempo de los Austrias a la luz de la legislación aplicable. De Computis - Revista Española de Historia de la Contabilidad, 5(9), 48. DOI: 10.26784/issn.1886-1881.v5i9.150

Donoso, A. (2010). Documentos relativos a la implantación de la contabilidad por partida doble en las Cajas Reales de Indias (1784). Sevilla: Asociación Española de Contabilidad y Administración de Empresas/Ilustre Colegio Central de Titulados Mercantiles y Empresariales de Madrid/Universidad de Sevilla.

Durán y Díaz, J. (2013). Estado General de todo el Virreynato de Santafé de Bogotá en el presente año de 1794. Bogotá: Banco de la República.

Ezpeleta, J. (1989). Relación del gobierno del excelentísimo señor don Josef de Ezpeleta. En G. Colmenares (ed.), Relaciones e informes de los gobernantes de la Nueva Granada (pp. 153-312). Bogotá: Fondo de Promoción de la Cultura del Banco Popular.

Friede, J. (1981). Rebelión comunera de 1781: Documentos (vol. 2). Bogotá: Instituto Colombiano de Cultura.

Jara, Á. (1994). El financiamiento de la defensa en Cartagena de Indias: los excedentes de las cajas de Bogotá y de Quito, 1761-1802. Historia, 28, 117-182.

Jara, Á. (2011). El imperio español en América: 1700-1820: una historia económica. Santiago de Chile: Sudamericana.

Kalmanovitz, S. y López, E. (2012). La Economía de Santafé de Bogotá En 1810. Revista de historia económica/Journal of iberian and Latin American economic history, 30(2), 191-223. DOI: $10.1017 / \mathrm{S} 0212610912000031$

Klein, H. S. (1973). Structure and profitability of royal finance in the viceroyalty of the Rio de la Plata in 1790. The hispanic american historical review, 53(3), 440. DOI: $10.2307 / 2512973$

Klein, H. S. (1994). Las finanzas americanas del Imperio español: 1680-1809. México: Instituto de Investigaciones Dr. José María Luis Mora /Universidad Autónoma Metropolitana-Iztapalapa.

Maqueda, C. (2007). El virreinato de Nueva Granada (1717-1780): estudio institucional. Madrid: Dykinson/Puertollano.

Marchena, J. (2005). Capital, crédito e intereses comerciales a fines del periodo colonial: Los costos del sistema defensivo americano. Cartagena de Indias y el sur del Caribe. En A. Kuethe y J. Marchena (eds.), Soldados del rey: El ejército borbónico en América colonial en vísperas de la independencia (pp. 3-38). Castelló de la Plana: Universitat Jaume I.

McFarlane, A. (1997). Colombia antes de la independencia: economía, sociedad y política bajo el dominio borbón. Bogotá: Banco de la República/El Áncora.

Meisel, A. (2011a). Crecimiento, mestizaje y presión fiscal en el virreinato de la Nueva Granada, 1761-1800. Cuadernos de Historia Económica y Empresarial, 28, 1-97. Recuperado de http://www.banrep.gov.co/es/ 
Meisel, A. (2011b). ¿Situado o contrabando? La base económica de Cartagena de Indias a fines del siglo de las luces. En Colección ¿̇Por qué perdió la costa Caribe el siglo XX? (pp. 9-58). Bogotá: Banco de la República.

Mora, G. L. (1983). Las cuentas de la Real Hacienda y la Política Fiscal en el Nuevo Reino de Granada: materiales para un estudio, a fines del siglo xviII. Anuario Colombiano de Historia Social y de la Cultura, 11, 305-335. Recuperado de https://revistas.unal.edu.co/

Moreno, N. (2013). Circulación de efectos de Castilla en el Virreinato de la Nueva Granada a finales del siglo XviII. Fronteras de la historia, 18(1), 211-249. DOI: 10.22380/2027468851

Muñoz, E. A. (2010). Estructura del gasto y del ingreso en la Caja Real de Santafé, 1803-1815. Anuario Colombiano de Historia Social y de la Cultura, 37(2), 45-85.

Muñoz, E. A. y Torres, J. V. (2013). La función de Santafé en los sistemas de intercambio en la Nueva Granada a fines del siglo XviII. Fronteras de la historia, 18(1), 165-210. DOI: 10.22380/20 27468850

Pérez y López, A. X. (1796). Teatro de la legislación universal de España e Indias, por orden cronológico de sus Cuerpos, y decisiones no recopiladas y alfabético de sus títulos y principales materias (vol. 10). Madrid: Imprenta de Ramón Ruíz. Recuperado de https://catalog.hathitrust.org/

Phelan, J. L. (1980). El pueblo y el rey: La Revolucion Comunera en Colombia, 1781. Bogotá: Carlos Valencia Editores.

Pinto, J. J. (2014). Fiscalidad e independencia en Panamá, 1780-1845. Tiempo y economía, 1(1), 11-37. DOI: $10.21789 / 24222704.943$

Pinto, J. J. (2015). Fiscalidad e Independencia en Santafé y Bogotá, 1780-1830. América Latina en la Historia Económica, 22(3), 7. DOI: 10.18232/alhe.v22i3.649

Pinto, J. J. (2016). Reconstrucción de series fiscales de las Cajas Reales de la Nueva Granada en la segunda mitad del siglo XVIII. Instituto Colombiano de Antropología e Historia. Bogotá: Instituto Colombiano de Antropología e Historia.

Pinto, J. J. (2018). Entre colonia y república: Fiscalidad en Ecuador, Colombia y Venezuela, 1780-1845. Bogotá: Instituto Colombiano de Antropología e Historia.

Pinto, J. J. y Díaz, C. A. (2016). Fiscalidad en Popayán, 1750-1821. Tiempo y economía, 3(2), 3354. DOI: $10.21789 / 24222704.1128$

Rodríguez, O. (1983). Anotaciones al funcionamiento de la Real Hacienda en el Nuevo Reino de Granada. Siglo xviII. Anuario Colombiano de Historia Social y de la Cultura, 11, 71-88. Recuperado de https://revistas.unal.edu.co/index.php/

Rodríguez, O. (1987). La caja real de Popayán 1738-1800. Anuario Colombiano de Historia Social y de la Cultura, 15, 5-36. Recuperado de https://revistas.unal.edu.co/index.php/

Rojas, J. (2001). El Tribunal de Cuentas de Santafé. Bogotá: Ediciones Cardozo.

Sánchez, E. (2013). Corte de caja: La Real Hacienda de Nueva España y el primer reformismo fiscal de los Borbones (1720-1755): alcances y contradicciones. México: Instituto de Investigaciones Dr. José María Luis Mora.

Sánchez, E. (2019). Ordenar las cuentas. La reforma contable de Tomas Ortiz de Landázuri (1766-1767) y su aplicación en la Real Hacienda de Nueva España. En Hacienda e instituciones. Los erarios regio, eclesiástico y municipal en Nueva España: Coexistencia e interrelaciones. México: Instituto de Investigaciones Dr. José María Luis Mora/Universidad Veracruzana.

Serrano, J. M. (2002). Apuntes para una metodología del estudio del gasto militar en Indias. Temas americanistas, $15,75-89$. 
Serrano, J. M. (2004a). Fortificaciones y tropas: El gasto militar en tierra firme, 1700-1788. Sevilla: Diputación Provincial.

Serrano, J. M. (2004b). Situados y Rentas en Cartagena de Indias durante el siglo xviII. Temas americanistas, $17,58-78$.

Serrano, J. M. (2006). Metodología en el análisis de las cajas reales: Técnicas para estudios de la administración militar en el siglo xviII. En J. Sánchez y L. Provencio (eds.), El Mediterráneo y América (pp. 953-957). Murcia: Editora Regional de Murcia.

Torres, J. V. (2013). Minería y moneda en el Nuevo Reino de Granada: El desempeño económico en la segunda mitad del siglo XVIII. Bogotá: Instituto Colombiano de Antropología e Historia.

Torres, J. V. (2014). Tasas de interés y desempeño económico: El crédito comercial en Santafé de Bogotá, 1760-1810. América Latina en la Historia Económica, 21(3), 9. DOI: 10.18232/alhe.v21i3.577

\section{Archivos}

ACc Archivo Central del Cauca, Popayán, Colombia.

AGI Archivo General de Indias, Sevilla, España.

AGN-C Archivo General de la Nación, Bogotá, Colombia.

John Jay TePaske Papers, David M. Rubenstein Rare Book \& Manuscript Library, Duke University, Carolina del Norte, Estados Unidos de América. 